\title{
Re-considering orientations in South African Language Policies
}

\author{
Chanel van der Merwe \\ Lecturer, Linguistics, Faculty of Humanities, Nelson Mandela University, \\ Summerstrand, Gqeberha, South Africa \\ chanel.vandermerwe@mandela.ac.za
}

\begin{abstract}
What should be taken into account when language policies are developed? It is rarely the case that when language policies are developed, the focus is on issues outside of 'language'. However, when issues of language are experienced in certain societies as a "cumulative disadvantage" (Piller 2016) together with other forms of domination, normative conceptualisations of language policy seem inadequate. The notion of 'inhabitance' is a generative lens through which to illustrate this. In the South African university space, since the \#MustFall protests, the question of 'inhabitance' has taken centre stage in issues of curriculum and access. Through the act of throwing poo on the statue of Cecil John Rhodes, the \#MustFall protests have firmly put on the agenda the need for universities to reflect upon itself, and to ask whose knowledges, bodies, histories and lifeworlds it legitimizes, and therefore, its complicity in maintaining coloniality. This has led to a wider call to decolonize universities. However, while the notion of 'inhabitance' has been central to the \#MustFall protests, it has not been considered from the position of language and language policy. This paper reflects on institution-wide language policy conversations at a South African university arguing to shift attention from the orientations we take to language in language policy, to how policies "orient" (Ahmed 2007) bodies in university spaces. This paper seeks to add to the conversation in the South African Higher Education space in anticipation of the implementation of the new Language Policy for Higher Education (2020).
\end{abstract}

\section{Keywords}

language policy - South African Higher Education - multilingualism - orientations 


\section{Introduction}

The field of Applied Linguistics has acknowledged that language is not a panacea, and there is a need for the field to be more responsive to socio-economic, racial and political issues (Flores and Chapparo 2018; Kubota 2014; Piller 2016), and also issues of cognitive justice (Pennycook and Makoni, 2020). In the field of language education policy, particularly, Flores and Chapparo (2018) have called "to broaden notions of what counts as language education policy to include the broader racial and economic issues that impact the lives of language-minoritized communities" (2018, 366-367). However, not infrequently, when there is talk of language and language policy, the focus is often on language only. When approaching the conceptualisation of language policy, analysts frequently take a decontextualized view which ultimately steers policy away from the lived experiences of the people which it impacts. Although sometimes there is some realisation of how decisions on language impact social variables like race, marginalisation, invisibilisation, 'inhabitance' and space, it is not often the case that in the conceptualisation and development of language policies the space is created for these variables to be agentive in the discussion of what a language policy should be. What orientations are we, then, taking that produce these conceptualisations of language policies that neglect how individuals experience language as intersecting with other domains of their experience?

Studies on language in the South African education space tend to be dominated by discourses of implementation (Kaschula \& Maseko 2014; Madiba 2013; Kaschula 2013; Makalela \& McCabe 2013), and to a lesser extent the analyses of the policy text itself (Antia \& Van der Merwe 2018), while there is a dearth of literature on how language policy is arrived at. At a local level, this produces recurring conversations on the language question' which starts from the position of the text, but never considers how the fundamental meaning of language policy can be different. This is problematic since failing to interrogate the basic concepts and assumptions that language policy takes as its starting points has "serious implications as the universal use of categories produces very similar narratives on what counts as language and language policies across the world" (Severo and Makoni 2020, 5).

Reflecting on the bottom-up language policy development process at Nelson Mandela University in South Africa, as well as my own ongoing research on language policy at this university, this paper aims to show how using Ahmed's framework of orientations (Ahmed 2007) broadens the spectrum of what are considered 'language-concerns' with a methodology that is more human-focused than language-focused. Furthermore, this paper 
asks how using orientations from the perspective of 'language experiences' can be relevant to argue for new 'arrivals' of language policy as we make a case for the role of African languages in the process of decolonising the university.

\section{Situating the Language Question in South African Higher Education}

In a recent survey (Gordon \& Harvey 2019) conducted by the Human Sciences Research Council, the think tank of South Africa's Humanities and Social Sciences, parents were asked whether they would prefer their children learn through English or in their mother tongue. From the survey, $65 \%$ of parents voted that they would prefer their children learn through the medium of English. While this is not surprising given the prevailing view that English affords more opportunity and mobility (McKinney 2016), it is the decontextualized nature of the question (especially coming from the think tank) that fails to historicize English, and fails to illustrate how the language is entangled with privilege and access, especially in spaces like education, that served problematic (McKinney 2016). In an interview (eNCA 2019) on a local news channel with Xolisa Guzula, a language expert from the University Cape Town, on the result of this survey, she argued that

I think it was wrong in the first place to ask the question do you prefer mother tongue or English. I don't' think that is the question we should be asking of parents, considering the facts of colonialism, considering the effects of apartheid which made us feel as Black people that we are inferior to any white person. Everything about us is inferior. So people are still harbouring those feelings of inferiority. So when you ask them whether they prefer home language or English, they will say English because English is seen as superior... the question of either/or does not help us.

Guzula's statement draws on broader national discourses that are taken up in language policies that position African languages in competition with colonial languages like English, and reduces the language question to "either/ or" discourses, or adding/subtracting discourses, as I have mentioned before (HESA 2010). This is illustrated in policies like The Language Policy for Higher Education (2002) (hereafter LPHE (20O2)) which is the first language policy to serve as a guideline for the use of language in universities post-apartheid. The LPHE (2002) fell victim to this discourse, and set a precedent for what is 
considered 'legitimate' languages, at a very sensitive and transformative point in our history, through the following provision 15.1:

The Ministry acknowledges the current position of English and Afrikaans as the dominant languages of instruction in higher education and believes that in the light of practical and other considerations it will be necessary to work within the confines of the status quo until such time as other South Africa languages have been developed to a level where they may be used in all higher education functions (LPHE 2002, 10.)

In this provision, the LPHE (20O2) states that South African indigenous language can be used as "languages of instruction" when they have a reached a "level" where they can be used. Though the requirements for this "level" is not explicitly stated, what is stated is that English and Afrikaans are already positioned at that "level". The LPHE (20O2) positions English and Afrikaans as the model of what a language ought to be in order for it to be used in higher education. This provision speaks to larger colonial discourses inherent in Applied Linguistics:

- It sets up dualistic discourses between English/Afrikaans and South African indigenous languages in terms of their 'legitimacy' for higher education, in terms of languages that are inferior and superior based only on their development in the formal aspects of language as opposed to the everyday uses of these languages

- This provision is also complicit in developing a limiting discourse of multilingualism as quantifiable, and based on abstract definitions of language (Banda 20o9; Makoni 1999)

- It positions African languages as perpetually needing to 'catch-up' (Blommaert 1994 as cited in Makoni and Meinhof 2003: $5^{-6}$ )

These discourses have given rise to a conceptualization of language policies that consider universities as custodians of the development of African languages, what Mkhize (2016) calls the "institutionalisation model" (2016: 146). At this point in time, virtually all South African universities have language policies that support multilingualism, and has 'taken up' at least one African language to 'develop'. While positioning universities as the custodians for developing African languages has been critiqued for its conservatism to this poject (Mkhize 2016), I would add to this critique the frustratingly narrow view with which this project has been taken up by the post-apartheid university and its perpetual misrecognition of the lived experiences of the Black staff and students who occupy these spaces. Looking at the broader field of Applied Linguistics, Kubota (2014) has noted similar concerns: 
Indeed, while our discipline engages with multi/plural frameworks, we continue to see not only the dominance of English and standard language ideology but also ethnic conflicts, civil wars, racism, xenophobia, and growing economic gaps both nationally and internationally. While applied linguistics alone will not cure these social evils, some are within the purview of our discipline, and the gap between our celebrated 'multi/ plural' perspectives and real lives of many people concerns me (2014:2).

At this point, I think it is important to locate South African university language policies within a 'politics of recognition'. While the development of African languages were supported through national language policies like the LPHE (2002), these initiatives should also be understood under a larger umbrella of how 'access' and 'transformation"' have been conceptualised in the post-apartheid university.

To a large extent, the inclusion of African languages in university spaces is part of a larger conversation on "access". When the post-apartheid university embarked on the post-apartheid transformation project, a large focus was put on "access" to the university space. However, as the Soudien report (DoE 2008) shows, this process was criticized for being too policy-driven, prioritizing demographic transformation over epistemological transformation, and not focusing on cultivating inclusive institutional cultures $(2008,40)$. For instance, transformation was viewed as giving more Black staff and students physical access to the space, without the imperative for the space to change in itself. In the realm of language, language policies were viewed as "an adding and subtracting exercise" (HESA 2010, 30). All universities had language policies that included some form of acknowledgment or promotion of multilingualism, but it was as if "having a policy [became] a substitute for action", it was as if transformation was achieved in the "act" of having a policy (Ahmed 2012, 11).

Almost a decade after the Soudien report showed "how fossilised institutional cultures and untouched curriculum were obstacles to the transformation of higher education and were alienating black students and black academics" (Lange 2017, 47), the \#MustFall protests echoed the same sentiments: scrutinizing the South African university, and whose interests it serves. The idea of whose lived experiences and norms are reflected in the university space was a central part of the \#RhodesMustFall and \#FeesMustFall protests. In these protests, students asked for greater economic and epistemological access to the university, the decolonization of white-centered knowledge, and

1 For an elaborated discussion on the transformation in education project and its role on language policy issues, see Van der Merwe (2016). 
the just treatment of workers via insourcing. Essentially, the protest was based on Black students and staff not "seeing" themselves in the institution; whether it is in spaces of knowledge production and knowledge dissemination, or whether it is in spaces of work, as bodies being ill-treated. These protests were "cr[ies[for fuller recognition" (Lange 2017: 49), "while simultaneously refusing and disrupting the possibilities of that very wish" (Mupotsa 2018: 23). There was an awareness that "the recognition of subordinated groups cannot fully take place unless a politics of distribution confronts the inequality and hierarchy on which lack of recognition is based" (Lange 2019: 87-8). Students and staff have illustrated how they come up against the whiteness of the institution (Ahmed 2012), in particular through the autobiographical ${ }^{2}$ - where they have "invoke[d] the category 'I' to articulate aspects of private life that animate their moves against structural injustices" (Mupotsa 2018: 23). One of the strongest illustrations of this has been \#Shackville - the moment when UCT students erected a shack on the stairs in front of Jameson Hall. ${ }^{3}$ While on the surface level \#Shackville was seen as a commentary on the lack of student housing, on a deeper level, it represented the failure of the transformation project. On the significance of this moment, Mpendukana and Stroud (2018) write:

\#Shackville was a tangible as well as existential 'presence of absence'. It was about students felt alienation and exclusion and their attempt to (re) claim a sense of ownership and agency for blackness in place. When the students built \#Shackville, they inserted themselves into a space where they were not welcome, thus performing a solidly material and physical manifestation of absence. In a sense, there is no better example of absence than not having space to be and making that absence tangible present in a space where it normatively should not be. However, by placing the shack-cum-portaloo on Jameson stairs in the middle of the night, the students were making an 'illicit' appearance, transgressing a boundary, not only of good behaviour, but a boundary that has historically marked the existential divide between whiteness and blackness (MPENDUKANA AND STROUD 2018: 186).

2 Many texts have been written on the \#MustFall protests in which staff and students have drawn on the 'autobiographical'. These include books like Black Academic Voices: the South African Experience (2019); Rioting and Writing: Diaries of Wits Fallists (2017), and articles like "Azania House as a Symbol of the Black Imagination" by Sebambo (2017) to name a few.

3 Jameson Hall, now known as Sarah Baartman Hall, is located at UCT. This Hall is typically used for graduation ceremonies. 
The meaning of \#Shackville and the broader \#MustFall movement that gave life to it illustrated the university's complicity in perpetuating understandings of transformation that misrecognises, particularly, the lived experieces of Black students and staff who occupy these spaces. It has illustrated how attempts at transformation have failed, and will continue to fail if these lived realities are not agentive in our conceptualisations of the 'post-apartheid university'.

\section{Orientations to Language Policies}

Against the backdrop regarding the state of South African universities, I would like to draw focus back to the main argument: A large part of the inadequacy in how language policies are conceptualised, as alluded to earlier, is the orientations (Ahmed 2006, 2012) that are taken that neglect how individuals experience language as intersecting with other domains of their experience, as argued by Piller (2016). This is based upon orientations that emerged out of my experiences as a Language Policy Working Group (hereafter LWG) member at Nelson Mandela University where we set out to develop a new language policy for the University using a bottom-up approach. When I arrived at Nelson Mandela University at the end of 2017, the University had just been renamed after the iconic statesmen, Nelson Mandela, which inspired many changes at the institution, among these, the development of a new language policy, not a revised policy. This was a very important point as part of the conceptualisation of the policy. At the end of 2017, we met to plan how this policy would be informed, and a few considerations needed to be taken into account: firstly, the new name of the university. Secondly, the development of the new Language Policy resided within the office of the Deputy Vice-Chancellor of Learning and Teaching and she was a strong advocate for Humanising Pedagogy, inspired by Paulo Freire, as the theoretical underpinning of all Learning and Teaching endeavours. Thirdly, the university's new vision to be a "dynamic, African institution", and lastly, the university's positionality in the Eastern Cape province of South Africa where isiXhosa is the dominant language spoken by $82.7 \%$ of the province's population (StatsSA 2016). We decided that we would take a bottom-up approach to the policy development and let the lived experiences of the university community inform the language policy (Lück 2020). We called this process 'courageous conversations about language'. These conversations were held over two years, spread across all seven campuses, and included all faculty and their students, academic staff, support staff (i.e administrators), departments (i.e HR, marketing, institutional planning, etc), and newly 
insourced staff (i.e from horticulture, cleaning services, catering, etc). These sessions only had two prompts: 1) what have been your language experiences at Nelson Mandela University, and 2) how do you envision an inclusive language policy at our institution? These sessions were conducted in any language/varieties/dialects the participants preferred. The role of the LWG was to sit and listen.

What I found in these conversations was that the narratives of the 'courageous conversations about language' were narratives of bodies and/in spaces: "...how some more than others will be at home in institutions that assume certain bodies as their norms" (Ahmed 2012, 3). What was also clear in the reflections was that whilst having conversations about language policy, we were also having conversations about the institution, and the orientations that the institution provides for thinking about diversity/difference. I began to think about the university and of language policy as "orientations" (Ahmed 2006, 2012). Orientation is an interesting concept to use when in fact it is also a well-known concept used in language policy studies. Ruiz (1984) developed the concept for language policy and planning defining it as "a complex of dispositions toward language and its role, and toward languages and their role in society" $(1984,16)$. However, in his use of the concept, attention is directed toward language, specifically viewing language as a resource, a problem, or a right. This concept, whilst useful, shifts the focus away from the speaking subject to language as an object. It aims to empower the language, but invisibilise the speakers. Ahmed's (2006; 2012) framework seems to better capture the experiences of these processes as this framework seems to privilege the body and its 'inhabitance' of a space $(2006,6)$. According to Ahmed $\left(2007,15^{2}\right)$

what comes into view, or what is within our horizon, is not a matter of what we find here or there, or even where we find ourselves, as we move here, or there. What is reachable is determined precisely by orientations we have already taken. Or we could say that orientations are about the directions we take that put some things and not others in our reach.

Furthermore, "[ $t]$ he starting point for orientation is the point from which the world unfolds: the 'here' of the body, and the 'where' of its dwelling" (2007, 151). These lenses became particularly generative in terms of thinking about the university and its technologies (like language policy) in enacting whiteness as its modus operandi (Flores and Rosa 2017). Over the course of two years, my involvement in this process has put me in a privileged position of listening to 
many 'language stories' of staff and students, as well as those on the periphery of the university. While these stories taught me the importance of listening, and the catharsis that comes with instituting platforms for storytelling, it was my own internal struggles with reconciling these language stories with normative conceptualisations of language policy, and the role that language policy is supposed to play in our institutions that brought me to this paper. This internal struggle found its embodiment in many instances over the past two years: it was those instances of participants seemingly veering 'off topic' when they started to speak about their working conditions and the awkward looks that were shot across the room that said this is not "language policy kind-of-conversations" that caught my interest and made me consider what language policy is (supposed to do). Some conversations followed a script - a common consensus of "these are appropriate responses" that fit a standard language next to a domain. When did we decide what is appropriate and what is not? I started to wonder what role the university as a space plays in managing these types of responses. It was also the recurring feeling of "what now" after walking away from each session. How is language policy supposed to capture what I just heard? Should a language policy be able to capture these experiences? Again, what is a language policy supposed to do?

The stories that were told and subsequent reactions to these stories brought to the fore the concept of 'inhabitance.'The notion of 'inhabitance' draws on the distinction Lefebvre (1996) made between "habitat" and "inhabit" where "habitat" alludes to a right to occupy or to be in a particular space but does not necessarily extend the courtesy to "inhabit" which refers to "the plasticity of space, its modelling and the appropriation by groups and individuals of the conditions of their existence" (Lefebvre 1996, 79). While Lefebvre uses these concepts in the realm of spatial planning, Van Marle (2019) argues that these lenses can be used as a jumping board to make a case for the "right to the university" brought up by students in the \#MustFall protests in South Africa.

In the following analysis, I reflect on five moments during, after and in-between the 'courageous conversations about language' where language was not the orientation, but rather how stakeholders 'inhabit' the university. In choosing these different moments, which reflect on the language conversations as well as draw on my own ongoing research, I aim to show the ripple effect these conversations had at the university, and the avenues it had opened. The intent of these reflections is to illustrate what happens when the broader lived experiences of stakeholders come up against normative conceptualisations of language policy in a university space, and how this expands how we come to understand language policy. 


\section{Lived Experiences of Language Policy}

Flores and Rosa (2017) argue that

...racially hegemonic perceptions can be enacted not simply by individuals but also nonhuman entities such as institutions, policies, and technologies associated with linguistic profiling (Baugh 2003), and not simply by white individuals but rather whiteness as an historical and contemporary subject position that can be situationally inhabited both by individuals recognized as white and non-white (Haney-Lopez 1996). (FLORES AND ROSA 2017,628$)$.

The university's orientation to whiteness is illustrated with examples that illustrate three themes when those who speak non-colonial languages are "made strangers" in university spaces.

\section{On Language and Knowledge}

The first moment I wish to draw on is an institutional seminar I attended on the topic of decolonising the university. This seminar (pre-Covid-19) was well-attended by students, and at the conclusion of it, I felt inspired. It was like a call to action. The first comment that was made was by a student. He said that he felt "oppressed" to not use his own language in this seminar. The theory did not find its way into practice. This comment was so powerful, and made me consider the different forms of (de)coloniality, especially Ngugi wa Thiongo's Decolonising the Mind (1986). This event was not part of the language conversations, but it took place during the same time that these conversations were happening on campus. With the spread of these conversations over two years and its reach across campus, I noticed that talking about language and bringing up the topic of language came up quite often outside of the confines of the language conversations. It was the ripple effects of the conversation opening up one space after the other.

This example sheds light on the paradoxes of the university: while talking about decolonisation which Ndhlovu-Gatsheni dubs as "a search for a liberating perspective aimed at facilitating self-understanding" $(2015,24)$, a student felt unable to use his own language, and used the word "oppressed" to express his feelings towards using English. What is also interesting is to critically interrogate what prevented the student from just speaking in isiXhosa when, in fact, the presenter was in a position to understand him as well as the majority of the audience members at the seminar. What this example illustrates, as perhaps a counter to Ahmed (2007), is not how institutions take on the shape of those 
bodies in close proximity, but rather, as Flores and Rosa (2017) point out, how institutions and policies as non-human entities enact whiteness $(2017,628)$. In this example, while the space enabled a critical dialogue about the hegemony of English, it did not allow space for it to be practiced. What are the implications for language policy from such an example? In referring back to McKinney (2016), if educational spaces and its technologies like language policies have been entangled in telling 'single stories' that position the language capacity of Black students as a deficit, are we surprised that the student did not take up the agency to speak in isiXhosa? When non-colonial languages have been included in limiting ways, how we write language policies, who it empowers, and the extent to which other languages are 'let in' are important factors to consider for how the policy will be taken up.

Learning and Teaching is an important sphere of the university in which to have these discussions as it comprises the knowledge dissemination (and to a certain extent also knowledge creation) aspects of the university. The extent to which languages are 'let in' is illustrated by a conversation I facilitated with a group of students from different disciplines. In the conversation, one contribution by a Health Sciences student stood out for me. This student, with dismay, asked how he could possibly ask an older woman about menstruation or contraceptives in a consultation when English does not allow him the sociolinguistic nuances to be culturally appropriate, taking into account issues of gender and age. The doctor-patient interaction that is expected from the student is brought into focus and is interrogated for its universality.

Though the student will meet the requirements of the course by presenting his consultation in English, this student brings with him his background, what he has learnt in the private sphere of his life. Is the university asking the student to leave this behind? The notion of 'inhabitance' is challenged yet again. What claims are the students making to the spaces when access is no longer just physical, but, as demanded by the \#FeesMustFall protests, access is questioned on the epistemological level as well. The student in this example, like the students of the \#FeesMustFall protests, is interrogating his right to be in the space (habitat) and also his right to be reflected in it - to inhabit it.

The plight of this student stands in contrast to the discussions around the popular solution of translation services for lectures and communications in the university. Will it be enough to merely use African languages as translation devices when using English in seemingly neutral and universal practices? In the case of healthcare practitioner-patient conversations - as the example above illustrates - are translations adequate to reflect the lived experiences of people? This example brings to the table the extent to which a language is included in spaces of Learning and Teaching whilst being mindful of the mandate by 
the new LPHE (2020) to use African languages as 'sources of knowledge'. In this realm, Magoqwana (2018) shares insights for how conceptualisations of language can be re-thought through her framework "Repositioning uMakhulu as an Institution of Knowledge". This framework, aside from its emphasis on indigenous languages, breaks down the "unnecessary separation between the informal and the formal institution" which encompasses divisions between "public and private, the household and state, and knowledge and spirituality". She states that

[i]n taking the so-called 'informal' institution as part of learning into the curriculum of our universities and schools, we are then forced to acknowledge the inseparability of the household and learning, the embodiment of knowledge and the inherent ancient African values carried by this boundary-less knowledge stretching back into pre-colonial era (MAGOQWANA 2018, 86).

This framework "restitch[es[the seams between indigenous and Western knowledges" (Stroud and Kerfoot 2013, 25). Constructing language policy through a framework like this eliminates the need for African languages to vie for their worthiness to be used in spaces of education. It is inherent through the fact that onus is not only placed on a language as an object to be used in spaces of education, but more significantly, it challenges who are considered knowledge holders. Magoqwana's (2018) framework does not include African languages for its capacity to translate knowledge that is already constructed, but for knowledge that it can offer. Thinking the new LPHE (2020) through Magoqwana's (2018) framework gives the new policy depth and provides spaces to have more nuanced conversations about what it might mean to include African languages as "sources of knowledge". This contributes to what Nuttall calls making the university walls "porous" (Nuttall 2019).

\section{The Newly-Insourced Workers}

The second theme that arises when when those who speak non-colonial languages are "made strangers" in university spaces relates to newly-insourced workers. Linked to issues of tuition fees and the decolonisation of the university curriculum, the \#FeesMustFall protests also took on the plight of workers on campus who have worked under precarious conditions for many years. For many of the students who took part in the protests, these workers represented their own mothers and fathers, grandmothers and grandfathers who most likely did not receive the same opportunities as they themselves had received since their elders had to endure the oppression of the apartheid 
system, more specifically Bantu education. ${ }^{4}$ One of the many revolutions of the \#FeesMustFall protests have been the insourcing of these workers into the university system which means economic stability and gives these new staff members opportunities to send their own children to study at the university for free. The success of the insourcing of these workers as staff members into the university, under the umbrella of the achievements of the \#FeesMustFall protests, are part of what Sarah Nuttall calls the "redistributed university" (Nuttall 2019):

I make use of the term in two different senses. First, in the sense of the call for a radical politics of reparation and change. This refers to an insistence on a renewed engagement with who occupies University structures and how, on whose behalf and to what ends; on a changed curriculum which draws much more fully on rich and often underrepresented traditions of black thought. It refers, too, amongst other issues, to a taking down of statues that have outlasted their time, archiving them if necessary so we can study their visual and political legacies. Calls for fee decreases or free education, and for the insourcing of workers, operate along redistributive logics deeply invested in social justice. $(2019,282$, EMPHASIS ADDED)

A university operating under what Nuttall (2019) deems "redistributive logics" as put forth by the \#FeesMustFall protests opens up interesting discussions for what Nuttall sees as a starting point to make the university walls more "porous", to challenge what "constitutes the inside and the outside" of the university. I argue that the newly insourced workers straddle this 'line'. The university, to some extent, was forced to employ these workers as a result of the protests, where in previous circumstances, workers were contracted to the university by private companies which means that the university did not have to show a responsibility toward their 'lifeworlds'. As new staff members, the workers bring the lived experiences of those on the margins of society 'inside' the elitist spaces of the university. In the following reflections, both related to newly

4 Language policies in the South African education context have been entangled in the apartheid strategy of 'separate development', especially for those classified 'Black' under the apartheid policy of racial classification. Bantu education was an act of violence against Black people through the development of an education policy in which inferior education was developed in direct relation to the roles that Black people were supposed to fulfil in society. African languages were a compulsory part of Bantu education, while other racial groups used the official languages of that period: English and Afrikaans (Webb, Lafon \& Pare 2010). Based on this, stigmas around African languages in education emerged. 
insourced workers, I use the lived experiences of these workers as a jumping board to challenge the role of language policy in universities.

During the language conversations, we had many conversations with the newly insourced workers. However, what stood out for me, particularly in these conversations, was the distinct role that language and communication played in instances of invisibilisation and autonomy. The newly-insourced workers are integral to the day-to-day running of the university, and their value has been particularly accentuated during Covid-19 where many workers have been deemed "essential workers" (Witswiser 2020). However, while the 'insourcing' of these workers into the university as staff members, and their indispensable role during a worldwide pandemic cannot be denied, it stands in contrast to their invisibilisation and, even erasure, purely based on English competency in their day-to-day lives at the workplace. For many of these workers, while their 'insourcing' makes them staff members on paper, their claims to be 'legitimate' members of the university community is still under question. These claims to 'legitimacy' came under scrutiny in the practices of Human Resources - particularly those of interviews, contracts, internal staff communication, and skill-building opportunities. Why is English the only language that is used to access these resources? That was the fundamental question.

In a conversation with the Human Resources department, language as a barrier came out as a strong issue in job applications and interviews at all postlevels. There is no opportunity to speak a language aside from English in any of these interviews, or even the skill-building opportunities that are developed for staff. In the conversation with the HR department, the process of insourcing workers after the \#MustFall protests was flagged as a particularly daunting experience that, in many instances, undermined the automony of these workers in making informed decisions about their own lives. This moment puts into question the normativity of English in spaces, like the university, that are located in a broader context where multilingualism is the norm.

The second moment, I wish to draw on speaks to the idea of 'family', but also speaks to a methodological question, specifically the concept of listening.

Who is considered to be family? This question was posed to me in a conversation one afternoon with some of the newly insourced workers. This had not been the first time this issue had been brought up, but it seems as if the language conversations (focusing on language experiences) provided a platform for these issues to be discussed. At first, I was not sure what was meant by bringing in this question. But there was a sense of shock that the definition of 
"family" that is used in university policies does not stretch beyond the biological children - a definition of "family" which is not reflective of many African cultures. ${ }^{5}$ The definition of family has implications for many other policies in the university like medical aids and academic rebates (this topic is not unique to this university only). Though this topic was brought up in a conversation about language policy, this points to

the language practices of those who are disadvantaged in other ways because of their legal status, their gender, their race, or their class - are usually the ways of speaking that are least valued, and language thus becomes one aspect of cumulative disadvantage in diverse societies (PILLER 2016, 14)

When I listened to this conversation, at first, I was unsure whether this contribution 'fit' the brief of developing a language policy. However, upon deep reflection on this point, I have come to understand that for many of these workers, issues of language exist at the intersections of other disadvantages like race, class and gender. The problem was not whether this contribution 'fit', rather the problem was how I was listening? Was I listening intersectionally? As academics, we are 'disciplined' by our disciplines (Keet 2018), and this is often the currency we bring to other spaces. As a person who needs to develop a language policy from a bottom-up perspective, I needed to acknowledge my own listening practices and assumptions going into the process, and how this might close down the lived experiences of those I am serving by being part of the development of a specific policy. This leads me well into the final theme that I wish to discuss and that relates to the process of the language conversations themselves.

\section{On Methodologies}

At the conclusion of the 'courageous conversations about language' as I read through the responses, I noticed that, in fact, the responses to the two prompts did not seem to match up. While the first prompt that asked about the participants' lived experiences with language seemed to stir deeper reflections

5 According to Siqwana-Ndulo (1998: 407), "in Western society, for example, "family" is generally understood to refer to the conjugal pair who maintains a household with their offspring or adopted children. Anyone else outside of this circle is "extended family." In African society generally, and among the Xhosa in particular, "family" refers to a much ider circle of people." 
on language as embedded in cultural processes, in social relations, as tied to emotion (as I have illustrated above), the second prompt asks for language policy solutions, seemed to block certain responses. It seemed that all solutions were filtered through normative/preconceived ideas of what the participants thought the institution allows - the most popular being "translation", "translation", "translation". The word "translation" saturated the conversations, and while the inclusion of isiXhosa is progress, the extent to which it should be included was never interrogated. It was as if having it there was deemed enough. While including an African language in a space like a university is very important, previous language policies have shown us that a language can be included for mere symbolic purposes (Cakata and Segalo 2017). This speaks to broader questions of 'inhabitance' - by giving the language the right to be used (via the language policy), to what extent is the university space showing a willingness to be changed by the language? It seemed as if the underlying discourses drew on the same apartheid colonial discourses of adding and subtracting languages. The differential responses to the two prompts bring up interesting questions about the methodologies that we use in spaces of higher education, even when it is meant to be democratic and inclusive, it can maintain ties to coloniality. As such, Grosfoguel (2016), in talking about the Western university, states that we need to

confront colonial methodologies that systematically block the asking of certain questions, a kind of methodological silencing that chokes the neck of bodies in a way that does not allow them to speak from their subaltern epistemic locations (2016, XII - XIII).

The experiences of the newly insourced staff members and other stakeholders bring to the fore the complicity of institutions in maintaining whiteness when the lived realities of those on the margins come up against the whiteness of the institution. These examples illuminate how language policy does not only speak to issues of medium of instruction and communication within the institution, but also how language issues can influence "...who occupies University structures and how, on whose behalf and to what ends" (Nuttall 2019,282 ). Issues of language have a stake in any debate on transformation and decolonisation. This begs the question who it serves when language policies are decontextualised from other policies in the institution or considered the responsibility of language departments only. The rich contributions made by the newly insourced workers asks us to consider how issues of language are situated in the university and shows us how people can be made 'strangers' when language is viewed as an 'add-on'. 


\section{Conclusion}

This paper asks us to consider that perhaps the reasons why language polices fail (beyond issues of implementation, funding, commitment - which are all important issues) is because of their lack of engagement with how language can be experienced as a "cumulative disadvantage" together with issues like race and class (Piller 2016). In the South African context, the use of African languages, as advocated for in multilingual language policies, have been central in the transformation of the South African Higher Education project (Van der Merwe 2016). As the \#MustFall movements have shown us, the transformation project has failed. The move to decolonize universities have been placed firmly on the agenda by staff and students, and the role of African languages have been identified as central to the project of decolonising South African universities (Mkhize 202O). What does this mean for language policy going forward?

This paper seeks to advocate for a closer emphasis on 'arrivals' of policies, and suggests that disregarding 'arrivals' of language policies has the tendency to perpetuate the same local conversations on the 'language question' which start from the position of the text, but never considers how the fundamental meaning of language policy can be different. This paper puts forward orientations as a methodological tool. It argues that the orientations we have applied in language policies from the perspective of language only, has positioned solutions as 'adding' more languages. If, as the LWG at Nelson Mandela University has shown, we orient the language policy from the perspective of language experiences, we see how language intersects with other domains of experiences. From the perspective of the racial, the political, and the socio-economic, this paper agrees with Flores and Chapparo (2018) who advocate for

a new paradigm of language activism that connects the implementation of language education policy with other movements that seek to address societal inequities caused by a myriad of factors including poverty, racism, and xenophobia. [They] argue that while policies that address these larger racial and economic factors may not explicitly focus on language education policy, they should count as language activism because of the ways that they affect the efficacy of language education programs that serve language-minoritized communities. (2018: 367$)$

At an epistemological level, this paper has shown that re-imagining language policies cannot be detached from the broader conversation on decolonizing universities since it is not only a question of whose languages are represented 
in a language policy, but rather whose 'lifeworlds' are we denying as legitimate frames of knowledge. In the advent of the new Language Policy for Higher Education (2020) which asks how African languages can be used as "sources of knowledge", how can language policies open up spaces for this aim to be accomplished?

While language policies are important for holding universities accountable, universities, and its technologies like language policies, have to deal with their entanglements with colonialism and apartheid and their orientations toward whiteness. Shifting orientations to language experiences has the ability to point out the decontextualised manner of using pre-determined models where the development of languages takes precedence over human concerns (Pennycook and Makoni 2020), which hopefully leads to a fundamental re-thinking of what the language policy should be, and the purpose it should serve in these contexts. From a methodological perspective, using orientations this way provides the opportunity for using a bottom-up approach which allows the space to question the domains of the university that are (re)produced in language policies. These domains, in most cases, only speak to research, teaching, and internal and external communication. Using orientations differently allows for broader questions on how the university is conceptualised (in a particular context), and who is considered to be a legitimate part of the "university community". These are important questions that can be brought up as we reflect on the role of African languages in decolonising the university that disrupts the tendencies of universities to be elitist and exclusionary.

This paper does not wish to posit language policies as panaceas. It also does not claim to have the answers to these complex questions. What this paper asks is for a situated view of language policies that are intersectional, but also dynamic in how universities approach language policies.

\section{References}

Ahmed, S. "A phenomenology of whiteness." Feminist Theory, 8, no 2. (2007): 149-168. Ahmed, S. On being included: racism and diversity in institutional life. London: Duke University Press, 2012.

Ahmed, S. Queer phenomenology: orientations, objects, others. London: Duke University Press, 2006.

Antia, B. \& Van der Merwe, C. "Speaking with a forked tongue about multilingualism in the language policy of a South African university." Language Policy, 18, no 3. 407429, 2018. 
Banda, F. "Critical perspectives on language planning and policy in Africa: Accounting for the notion of multilingualism." Stellenbosch Papers in Linguistics PLUS, no $3^{8 .}$ (2009): 1-11.

Cakata, Z. \& Segalo, P. "Obstacles to post-apartheid language policy implementation: Insights from language policy experts." Southern African Linguistics and Applied Language Studies, 35, no 4: (2017): 321-329.

Department of Education. Report of the ministerial committee on transformation and social cohesion and the elimination of discrimination in public Higher Education institutions. Pretoria: Department of Education, 2008.

eNCA (2019) 65\% of parents want their children to be taught in English. [online video] Available at: https://www.youtube.com/watch?v=a89U8GAq4eM [Accessed 12 March 2020].

Flores, N. \& Chapparo, S. "What counts as language education policy? Developing a materialist Anti-racist approach to language activism". Lang Policy 17: 365-384, 2018.

Flores, N. \& Rosa, J. “Unsettling race and language: Toward a raciolinguistic perspective.” Language in Society, no 46, (2017): 621-647.

Gordon, S. \& Harvey, J. 2019. South Africans prefer their children to be taught in English. The Conversation [online]. URL: https://theconversation.com/ south-africans-prefer-their-children-to-be-taught-in-english-124304.

Grosfoguel, R. "The dilemma of ethnic studies in the United States: between liberal multiculturalism, identity politics, disciplinary colonisation, and decolonial epistemologies". In Decolonizing the Western university: interventions in philosophy of education from within and without, edited by R, Hernández, \& R, Velásquez. New York: Lexington Books, 2016.

Higher Education South Africa. Sector position paper on the report of the Ministerial Committee on transformation and social cohesion and the elimination of discrimination in South Africa's public Higher Education institutions. Pretoria: Higher Education South Africa, 2010.

Kaschula, R.. Multilingual teaching and learning models at South African Universities: opportunities and challenges. Seminar Presentation at Rhodes University, March 2013 .

Kaschula, R.H. and Maseko, P. "The intellectualisation of African languages, multilingualism and education: A research-based approach." Alternation special edition, no 13, (2014): 8-35.

Keet, A. The plastic university: knowledge, disciplines and decolonial circulations. Inaugural Lecture. Nelson Mandela University, 2018.

Kubota, R. "The Multi/Plural Turn, Postcolonial Theory, and Neoliberal Multiculturalism: Complicities and Implications for Applied Linguistics". Applied Linguistics (2014): 1-22. 
Lange, L. "20 years of Higher Education curriculum policy in South Africa." Journal of Education., 68, (2017): 31-58.

Lange, L. The institutional curriculum, pedagogy, and the decolonisation of the South African University. In Jansen, J. (ed). Decolonisation in universities: the politics of knowledge. Johannesburg: Wits University Press, 2019.

Lefebvre, H. Writing on cities. Oxford: Blackwell Publishers Inc, 1996.

Lück, J. Rethinking Linguistics at Nelson Mandela University: Emerging decolonial insights. In Turner, I, Brahima, A \& Woldegiorgis, E. (eds). Decolonisation of higher education in Africa Perspectives from hybrid knowledge production. London: Routledge, 2020.

Madiba, M. "Multilingual education in South African universities: Policies, pedagogy and practicality." Linguistics and Education, 24, no 4 (2013): 385-395.

Magoqwana, B. "Repositioning uMakhulu as an Institution of Knowledge." In Whose History Counts: Decolonising African Pre-colonial Historiography edited by Bam, J; Ntsebeza, L \& Zinn, A. Stellenbosch: African Sun Media, 2018.

Makalela, L. \& McCabe, R. "Monolingualism in a historically Black South African University: A case of inheritance." Linguistics and Education, 24, no 4 (2013): 406-414.

Makoni, S. "Shifting discourses in language studies in South Africa". In Knowledge in Black and White: the impact of apartheid on the production and reproduction of knowledge, edited by Prah, K. Cape Town: Centre for Advanced African studies, 1999.

Makoni, S. \& Meinhof, U. "Introducing applied linguistics in Africa." AILA Review 16 (2003), 1-12.

McKinney, C. Language and Power in Post-Colonial Schooling: Ideologies in Practice. New York: Routledge, 2016.

Mkhize, N. "Away with Good Bantus: De-linking African language literature from culture, 'tribe' and propriety." Arts \& Humanities in Higher Education, Vol. 15(1): 146-152, 2016.

Mkhize, T. "The Role of African Languages in Decolonising South African Universities." In The transformative power of language: from postcolonial to knowledge societies in Africa, edited by Kaschula, R \& Wolff, H. Cambridge: Cambridge University Press, 2020.

Ministry of Education. Language Policy for Higher Education. South Africa: Ministry of Education, 2002. URL: https://www.dhet.gov.za/Policy\%2oand\%2O Development\%2oSupport/Government\%2oNotice\%2oRevised\%2oLanguage\%2O Policy\%2ofor\%2oHigher\%2oEducation.pdf.

Ministry of Education. Language Policy for Higher Education. South Africa: Ministry of Education, 2020. URL: https:/www.gov.za/sites/default/files/gcis_ document/202011/4386ogon116o.pdf. 
Mpendukana, S. \& Stroud, C. “Of monkeys, shacks and loos: Changing times, changing places." In Making sense of people and places in linguistics landscapes, edited by Peck, A; Stroud, C and Williams, Q. London: Bloomsbury, 2018.

Mupotsa, D. "A Question of Power". In What Politics?: Youth and Political Engagement in Africa, edited by Oinas, E; Onodera, H \& Surpää, L. Leiden: Brill, 2018.

Ndhlovu-Gatsheni, S. "Decoloniality in Africa: a continuing search for a new world order." Australasian Review of African Studies, no 36 (2015): 22-5o.

Nuttall, S. "Afterword: the shock of the new old." Social Dynamics, 45, no 2. (2019): 28o-285.

Pennycook, A. \& Makoni, S. Innovations and challenges in applied linguistics from the Global South. New York: Routledge, $202 \mathrm{O}$.

Piller, I. Linguistic Diversity and social justice: An introduction to Applied Sociolinguistics. New York: Oxford University Press, 2016.

Ruiz, R. "Orientations in language planning." NABE journal 8, no 2, (1984): 15-34.

Severo, C. \& Makoni, S. "Solidarity and the politics of 'us': How far can individuals go in language policy? Research methods in non-Western contexts." In The Routledge Handbook of Research Methods in Applied Linguistics edited by J, McKinley \& and $\mathrm{R}$, Heath. New York: Routledge, $202 \mathrm{O}$.

Siqwana-Ndulo, N. "Comparative perspectives on Black family life: Volume II." Journal of Comparative Family Studies 29, No. 2 (Summer 1998): 407-417.

Stats, S.A. (2016). Provincial Profile: Eastern Cape Community Survey. http://cs2o16. statssa.gov.za/wp-content/uploads/2018/o7/EasternCape.pdf

Stroud, C. \& Kerfoot, C. "Towards rethinking multilingualism and language policy for academic literacies." Linguistics and education, 24, no 4. (2013): 396-405.

Van der Merwe, C. 2016, "Analyzing university language policies in South Africa: Critical discourse and policy analysis frameworks", MA thesis, Department of Linguistics, University of the Western Cape, South Africa.

Van Marle, K. "A "right" to the university." Acta Academica, 51, no 1. (2019). 109-124. wa Thiongo, N. Decolonising the mind: The politics of language in African literature. Nairobi: East African Educational Publishers Ltd, 1986.

Witswiser (2020) Sarah Nuttall: The Redistributed University [Accessed online: 15 June 2020] URL: https://witswiser.podbean.com/e/sarah-nuttall-the-redistributeduniversity/. 